\title{
Elites intelectuales e imaginarios sociales contrapuestos en la era del "millagro mexicano" y su expresión en la revista Cuadernos Americanos
}

\section{Lidia Girola*}

\section{Resumen}

En este artículo propongo la noción de imaginarios socioculturales como ideas y supuestos de trasfondo que conforman el horizonte cultural de una época en una sociedad determinada. La hipótesis que guía el trabajo es que esas ideas y supuestos son múltiples, y que frente a una "misma" situación, distintos grupos pueden sostener imaginarios contrapuestos. El período objeto de estudio es el que comprende las décadas de los años cuarenta y principios de los cincuenta del siglo veinte en México, que es conocido como la era del "milagro mexicano", cuando la Revolución se institucionaliza y el objetivo primordial de los gobiernos es la modernización del país. Los grupos estudiados son algunos de los que formaban parte de las elites intelectuales del momento.

Palabras clave: Imaginarios socioculturales. Elites intelectuales. México. Imaginario de la blanquitud. Imaginarios del indio.

\footnotetext{
*Universidad Autónoma Metropolitana Azcapotzalco, México.
} 


\section{Intellectual elites and social imaginaries contrasted in the era of the "Mexican miracle" and their expression in the journal Cuadernos Americanos}

\section{Abstract}

In this paper, I propose the concept of sociocultural imaginaries as background ideas and assumptions that define the cultural limits of an era in a given society. The hypothesis that guides the paper is that these ideas and assumptions are multiple, and that before a "same" situation, different groups can hold opposing imaginaries. The period under study comprises the 1940s and early 1950s in Mexico, which is known as the era of the "Mexican miracle", when the Mexican Revolution was institutionalized and the primary objective of governments was the modernization of the country. The groups studied are some of those belonging to the intellectual elites of the time.

Key words: Sociocultural Imaginaries. Intellectual elites. Mexico. Imaginary of Whiteness. Imaginary of Indians.

\section{Introducción}

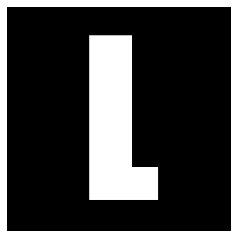

os años cuarenta del siglo XX y los primeros años cincuenta son conocidos como la era del "milagro mexicano". El llamado "milagro" consistió en los procesos de modernización del país, iniciados en la década de 1940 por el gobierno de Ávila Camacho, continuados al fin de esa década y comienzos de los años cincuenta por Miguel Alemán, y que prosiguieron en los gobiernos posteriores.

De ser un país principalmente agrícola, con altas tasas de analfabetismo y escasas urbanización e industrialización, el período post revolucionario, una vez alcanzadas la estabilidad política y el dominio del partido único (PNR primero y luego PRI: Partido Revolucionario Institucional), se 
caracterizó por un desarrollo acelerado de diversas industrias, favorecido por la segunda guerra mundial. La situación, crítica en un principio, significó una gran oportunidad para México, ya que permitió un incremento de las exportaciones hacia los Estados Unidos, y el apoyo de ese poderoso vecino para resolver el conflicto que, en el gobierno de Cárdenas, a fines de los años treinta, se había suscitado con las compañías petroleras, sobre todo inglesas, por la nacionalización del petróleo.

Ese período es también de una gran efervescencia social e intelectual $y$, como resultado de ello, surgieron varias empresas culturales que perduraron en los años venideros, y que fueron de una importancia crucial en el horizonte cultural mexicano.

Abonando ese desarrollo cultural, diversos sectores de la intelectualidad mexicana, algunos con estudios en el exterior, y los exiliados españoles, después de la derrota de la República en la Guerra Civil Española (1936/1939), se dedicaron, durante esos años cruciales, a expresar y debatir acerca de los problemas de México e Iberoamérica. Fue en el contexto de esos debates que aparecieron "imaginarios contrapuestos" acerca de la nación mexicana y las demás naciones de Latinoamérica, y su papel en el concierto mundial, tanto en el momento de la Segunda Guerra Mundial (1939/1945) como después. También, imaginarios de más larga data, como los que tenían que ver con la conquista y colonización, los indios y sus costumbres, y la dualidad modernidad/tradición, aparecieron en las páginas y manifiestos que en esa época circulaban en México.

En este texto, voy primero a comentar de manera muy breve la situación prevaleciente en la sociedad mexicana del período. Luego, mencionaré también de manera breve algunos grupos de la elite intelectual mexicana y de los llegados al país como consecuencia de la guerra civil española que voy a considerar y, finalmente, haré un repaso de esos "imaginarios contrapuestos" sustentados por esos grupos, tomando como muestra los que aparecen en las páginas de Cuadernos Americanos. 
A pesar de que las referencias históricas al periodo son bastante conocidas, creo sin embargo de cierta utilidad hacer un breve repaso de la situación política, cultural y económica por la que atravesaba México en esas décadas cruciales de su historia, las de los años cuarenta y comienzos de los cincuenta del siglo XX.

Tomar ese momento en especial y no uno más cercano a nosotros puede, de alguna manera, proveernos de una cierta objetividad derivada de la relativa lejanía en el tiempo, aunque la actualidad de los problemas que en ella se presentan es patente para cualquier observador.

Los ideales de la Revolución Mexicana iniciada en 1910, terminados los conflictos armados y a pesar de que en el gobierno seguían las luchas por el poder entre diferentes grupos, continuaron como referentes normativos revisados y re-significados a lo largo del tiempo. Estos eran ideales acerca de la libertad política que implicaba, entre otras cosas, elecciones limpias sin posibilidad de re-elección; el derecho a la tierra que suponía acabar con los latifundios, y el reparto agrario; el desmantelamiento de la estructura jerárquica de la sociedad; la organización obrera y la consecuente mejora en el nivel de vida de las clases populares; y el nacionalismo, que implicaba la soberanía sobre los recursos y la defensa de los intereses de México por sobre los extranjeros. Estos ideales se sintetizaban en el lema maderista de "Sufragio efectivo, no reelección" y el lema zapatista "Tierra y libertad", que guiaron no sólo a un sector de revolucionarios, sino a los gobiernos de Calles y sobre todo al de Lázaro Cárdenas en las décadas de los años veinte y treinta.

La democracia representativa tal como la conocemos ahora nunca fue un ideal de todos los revolucionarios.

Las décadas de los años cuarenta y cincuenta del siglo XX en México, el periodo denominado de Estado posrevolucionario, fueron un momento de especial efervescencia social, política, económica y cultural, 
en el que, junto con grandes cambios en la sociedad mexicana, varios imaginarios en pugna y convivencia definieron el derrotero de México como sociedad y como Nación.

En ese momento, es posible constatar una ambivalencia o duplicidad que permeó la vida de la época: discursivamente, siempre se sostuvieron los ideales del nacionalismo revolucionario y la justicia social, al punto de que aún los opositores y las clases dominantes los aceptaban como legítimos; pero, en la realidad, la meta del crecimiento económico, que culminó en el llamado "milagro mexicano", sustituyó a todo proyecto de reforma social profunda.

Otra cuestión a tener en cuenta es que México, según un dicho comúnmente aceptado, "es muchos Méxicos". Por una parte, al inicio de la década de los años cuarenta, en el país tenía todavía una cultura rural profundamente arraigada, con lo que eso conlleva: la mentalidad campesina era cerrada, desconfiada de los cambios, resistente a la incursión de "fuereños" (Niblo, 1999, cap. 1)

Por otra parte, existen en ese momento procesos de urbanización e industrialización acelerados, que condujeron a que los principios de la Revolución cambiaran sustantivamente: de una visión cuasi socialista de la distribución de la riqueza y de los contenidos de la educación, en el periodo de Cárdenas, se pasó a considerar como meta fundamental la modernización de México. Los objetivos de los gobiernos de Ávila Camacho y Miguel Alemán fueron fundamentalmente la industrialización y el crecimiento, en un marco de estabilidad social (pero con gran corrupción) que implicó mejorar las relaciones con poderosos grupos empresariales, con los Estados Unidos, e incluso, después de los conflictos religiosos de la década de los treinta (período de la "guerra cristera" que implicó ataque a las iglesias y persecución a los ministros de culto, por sus ideas reaccionarias), mejoraron las relaciones con la Iglesia. 
Varias circunstancias confluyeron y abonaron la efervescencia social y cultural de la época: hay que tener en cuenta tanto las consecuencias de la Guerra Civil española, que llevó a México a un número notable de exiliados republicanos españoles, que en su gran mayoría se afincaron definitivamente en la nueva tierra; como la Segunda Guerra Mundial, que implicó un cambio profundo de política económica por parte de México, que entró de lleno a lo que conocemos como sustitución de importaciones, y que dio un impulso grande a la economía, porque los Estados Unidos requirieron productos mexicanos como nunca antes. La modernidad alemanista estuvo marcada por la inmensa influencia de los modos de vida y los nuevos artefactos del confort norteamericano; la cultura estadounidense, según Daniel Cosío Villegas, era "como el dios de los cristianos: todopoderosa y omnipresente" (Krauze, 2015, p. 193). El estilo de vida norteamericano, pero con escenografía mexicana, se volvió el ideal de las clases medias (Loaeza, 2010, p. 670).

El régimen fue autoritario (nada obstaculizaba la voluntad presidencial), represor con los disidentes y, sin embargo, a decir de Soledad Loaeza, el mecenazgo estatal fomentó la creatividad artística y de innovación en las letras y el pensamiento. Según Stephen Niblo, el aliento oficial a los artistas e intelectuales, que comenzaron a vivir dentro del presupuesto estatal, fue una manera de cooptarlos y tenerlos atrapados (Niblo, 1999, cap. 4). Sin embargo, y más allá de las motivaciones del gobierno, es un hecho que la cultura y las artes florecieron en el sexenio. Durante el gobierno de Miguel Alemán, se inauguraron la Ciudad Universitaria y el Instituto Nacional de Bellas Artes. El cine mexicano vivió una de sus épocas más fructíferas, la radio llegó a los hogares de la mayoría de los mexicanos y luego la televisión, aunque sólo en las clases acomodadas fueron elementos importantísimos en la cultura de los mexicanos. 
El clima intelectual era de exaltación patriótica y toma de conciencia de lo propiamente mexicano; los artistas pintaron, escribieron y musicalizaron temas populares, y la plana mayor de la joven generación de universitarios fue convocada y promovida en diversos puestos importantes del gobierno.

Ese es el momento histórico que me propongo comentar.

II

En este apartado ${ }^{1}$, voy a considerar dos grupos de intelectuales ${ }^{2}$ con gran peso en el ambiente cultural de la época: por un lado, la llamada "Generación del 15", los hombres que tenían entre 17 y 20 años al finalizar la Revolución Mexicana y que, para las décadas que nos interesan, estaban en su mediana edad. Este grupo tuvo, por lazos de amistad o por coincidencias en su formación (muchos habían pasado por la Escuela Nacional Preparatoria y/o la Escuela de Jurisprudencia), un papel protagónico en la historia del país. Algunos tenían una clara vocación política y desde sus años más tiernos desempeñaron cargos en diversas instituciones; otros estuvieron directamente involucrados en las empresas culturales que comenzaron a florecer en el período que nos ocupa. Pero, por lo general, ambas vocaciones, la de servidor público y la de académicos e intelectuales, más el ejercicio de profesiones liberales, estuvieron presentes en un momento u otro, en todos los miembros de la Generación. Los militares que habían hecho la Revolución eran, por lo general, poco ilustrados, incultos, y no tenían un equipo ni asesores confiables en el terreno de las políticas públicas. El Estado que surgió después necesitaba de estos hombres capacitados en diversas disciplinas, ya fuera como con-

${ }^{1}$ Esta sección es una síntesis apretada de lo ya trabajado en un texto anterior (Girola, 2016)

${ }^{2}$ Debo aclarar que otros grupos de intelectuales tuvieron peso en la conformación del horizonte cultural mexicano de la época, pero por razones de espacio voy a considerar sólo a éstos, que participaron de manera importante en la revista Cuadernos Americanos. 
sejeros, representantes en el exterior o directamente como funcionarios. Los hombres de la Generación del 15 no habían hecho la Revolución, pero se consideraron sus herederos, porque asumían sus ideales y objetivos (Krauze, 2014, p. 65). Y a diferencia de otros grupos (los del Ateneo, de una generación anterior, por ejemplo), consideraron que su papel no era sólo el de promover la cultura sino el de estudiar los problemas de la sociedad mexicana, principalmente los del campo y los económicos, para encontrar las soluciones que la nación requería. Por ejemplo, Daniel Cosío Villegas, que en su momento se vio beneficiado con becas, subvenciones gubernamentales y cargos diplomáticos, comenzó a cuestionar el rumbo que iba tomando el país, y ciertos mitos de origen que impedían conocer las limitaciones y los desafíos que se enfrentaban. Entre esos mitos, estaba el de que México era un país rico, algo así como "el cuerno de la abundancia". Este mito, impulsado inicialmente desde la colonización por Bernal Díaz del Castillo y luego por Humboldt, ocultaba las tremendas carencias materiales del país que los hijos de la Revolución tenían que afrontar e intentar resolver. E incluso, Cosío cuestionaba las interpretaciones sobre los males mexicanos que otros miembros de la generación publicaban, porque decía que no estaban basados en estudios serios, científicos, de la realidad nacional. En varios artículos y sobre todo uno en Cuadernos Americanos, Cosío Villegas se explayó acerca de lo que él llamaba "la crisis de México" (Cosío Villegas, 1947). Otros miembros de la que posteriormente se denominó Generación del 15 realizaron estudios en el extranjero y, a su regreso, ocuparon diversos cargos en el gobierno mexicano ${ }^{3}$. Si hay algo que es común a este grupo de elite de la intelectualidad mexicana ${ }^{4}$ es que todos, a pesar de sus diferentes trayectorias,

\footnotetext{
${ }^{3}$ Cosío fue a Harvard, a la Universidad de Wisconsin y luego a Cornell; Espinosa de los Monteros a Harvard, Palacios Macedo a París; también viajaron, como funcionarios y para aprender, Gómez Morin y Eduardo Villaseñor, amigo íntimo de Cosío.

${ }^{4}$ En un trabajo anterior se mencionan los orígenes de clase y las trayectorias familiares de algunos de los miembros relevantes de esa elite intelectual.
} 
tuvieron lazos con los gobiernos en turno, porque vivir completamente fuera del presupuesto estatal era perder la oportunidad de incidir en el derrotero del país.

A los 35 años, algunos de los miembros de este grupo sentían que la Generación había fracasado en sus anhelos de cambio. Sin embargo, fue el momento en que comenzaron a reorientar sus proyectos. El caso de Cosío es paradigmático: convencido de la necesidad de que los economistas mexicanos accedieran a la bibliografía clásica y a los debates internacionales en la materia, consiguió financiamiento de diversas fuentes: el gobierno, amigos funcionarios, empresas, fundaciones extranjeras, y fundó una revista, El Trimestre Económico y una editorial, el Fondo de Cultura Económica (FCE), en 1934. Si bien sus aspiraciones de ser Secretario de Relaciones Exteriores de México se vieron truncadas, esto hizo que se dedicara a hacer estudios que el gobierno le encargó, y a una cada vez más intensa labor editorial; también propuso y promovió la labor de los refugiados españoles como traductores, maestros y pensadores; y logró la independencia de la industria cultural mexicana con respecto a las editoriales españolas.

III

El otro grupo de intelectuales objeto de este estudio es el de los españoles que arribaron a México como consecuencia de la derrota republicana en la Guerra Civil española, que se constituyó en un hito importantísimo para la cultura en México. Por influencia de Cosío Villegas, el gobierno mexicano inició la llamada "Operación inteligencia", que permitió que los exiliados, profesores e investigadores en diversas disciplinas fueran acogidos por instituciones mexicanas, principalmente la Universidad Nacional y la Casa de España en México, y posteriormente El Colegio de México, una de las instituciones educativas cuyo prestigio se 
fue consolidando desde entonces y hasta la actualidad. Como una muestra del importante papel del exilio español en El Colegio de México, se puede mencionar que el Centro de Estudios Sociológicos fue dirigido por José Medina Echevarría, quien en los breves años en que allí se desempeñó dejó la semilla para el desarrollo de la sociología de manera formal y académicamente consistente. Raimundo Lida, otro transterrado, dirigió el Centro de Estudios Lingüísticos desde 1947 y atrajo desde Argentina, donde la situación política no era favorable, la Revista de Filología Hispánica, que se publicó a partir de entonces en México, con la colaboración de la Universidad de Harvard de los Estados Unidos (Garciadiego, 2015).

Krauze señala que "la inventiva cultural de Cosío Villegas inició un pequeño milagro: convertir un exilio en una empresa, un destierro en un floreciente transtierro" (Krauze 2015, p. 120).

Los transterrados españoles, derrotados de la República, encontraron en México un nuevo hogar, y la posibilidad de continuar con sus vidas y sus carreras. Muchos trabajaron para el Fondo de Cultura Económica, como traductores y también como autores. Otros, que tenían profesiones liberales, lograron encontrar un camino en el ejercicio privado, o en la Universidad Nacional. Todos traían un recuerdo amargo de sus experiencias, y la mayoría, un cúmulo de expectativas con respecto al país que generosamente los había recibido.

\section{IV}

Cuadernos Americanos es una revista fundada a inicios de la década de los cuarenta, en la cual confluyen actores de diverso origen y orientación, mexicanos como el escritor Alfonso Reyes, españoles transterra$\operatorname{dos}^{5}$ a México como el filósofo José Gaos y las más importantes figuras del pensamiento iberoamericano del momento; es una revista en la que

\footnotetext{
${ }^{5}$ Según la feliz expresión del filósofo español José Gaos.
} 
tienen lugar debates sustantivos y sustanciosos acerca de múltiples problemas: la crisis mundial y mexicana; los problemas de la identidad; el papel y el futuro de la cultura.

Con la idea de generar un órgano de debate y difusión de ideas, varios españoles desterrados habían fundado España Peregrina, una revista que duró muy poco tiempo, y que fue sustituida por otra, Cuadernos Americanos, que tenía una vocación incluyente y la aspiración de incidir y trascender al ámbito iberoamericano. Los fondos para tal empresa no podían provenir del exilio español, así que los españoles Juan Larrea, León Felipe y Ortiz de Montellano acudieron al economista mexicano Jesús Silva Herzog, en su despacho de la secretaría de Hacienda, donde estaba a cargo de la oficina de Estudios Económicos, para solicitarle su apoyo. Tal como se relata en cartas del mismo Larrea, Silva Herzog se mostró entusiasmado con la idea de la revista y se ocupó de conseguir, a través de varios contactos y amigos (la idea de un solo mecenas fue desechada para garantizar la independencia de la publicación) los fondos necesarios para la empresa. En febrero de 1942 apareció el primer número, cuya portada reflejaba ya las ideas que la nutrían: unas ondas (que cambiaban de color en cada número) simbolizaban el mar ${ }^{6}$, que había que atravesar para llegar a "la tierra de la esperanza", aquella donde los ideales de la civilización, amenazados por la guerra en Europa, florecerían. Si el capital y el ingenio para conseguirlo provinieron de la parte mexicana, al igual que aportes intelectuales de valor, el aporte ibérico fue de extrema importancia: no hay que olvidar que los transterrados españoles provenían de la "Edad de Plata" del intelecto en España7, y muchos de ellos, aparte de hablar lenguas extranjeras, habían estudiado en Alemania, Italia y los

\footnotetext{
${ }^{6}$ Liliana Weinberg reseña el simbolismo que la portada implicaba: el mar del encuentro, el mar del tránsito, el mar liberador de hombres, de unión de civilizaciones (Weinberg, 1995). ${ }^{7}$ Muchos de ellos se habían formado en la Institución Libre de Segunda Enseñanza y pudieron continuar sus estudios en el extranjero con el apoyo de la Junta para la Ampliación de Estudios.
} 
Estados Unidos y eran excelentes traductores. "El exilio cultural español se vio obligado a asumir que no podía continuar viviendo en la aislada burbuja de la diáspora" según palabras de Ana González Neira (2009, p. 15) La confluencia de mexicanos y españoles dio un gran impulso a la revista, cuyo nombre se debe a Alfonso Reyes ${ }^{8}$. Juan Larrea fue secretario de la revista durante sus primeros ocho años, y su labor, impresionante, fue la que permitió que la revista sobreviviera.

En la Junta de Gobierno de la revista había seis mexicanos y cinco españoles.

La edición fue muy cuidada, con fotografías e ilustraciones que expresaban gráficamente los ideales de la revista. Sobre la importancia de ese material, volveré más adelante.

En los inicios de Cuadernos Americanos, la impronta de Larrea no fue sólo la de su papel como administrador y casi como "hombre orquesta". Su visión sublimada de América, la gran esperanza de la humanidad frente al derrumbe de España y de toda Europa durante la contienda, permea tanto sus escritos en la revista como la elección de los temas y la iconografía. Esa visión es compartida en cierta medida por otros españoles transterrados, como Eugenio Ímaz y León Felipe. Sobre esto también volveré más adelante.

Algunos de los colaboradores españoles de la revista escriben reiteradamente en ella: José Gaos, Juan Larrea, Eugenio Ímaz, José Medina Echavarría, León Felipe, Francisco Giner de los Ríos, Joaquín Xirau, entre otros.

Los destacados intelectuales mexicanos que colaboraron intensa y extensamente en la revista fueron, entre otros, Alfonso Caso, Daniel

\footnotetext{
${ }^{8}$ La historia de Reyes es sumamente ilustrativa de las diversas confluencias que conformaron el horizonte de la cultura en México: hijo de un general leal a Porfirio Diaz, la familia Reyes tuvo que emigrar a Europa durante la Revolución. Alfonso Reyes, un literato reconocido, después de desempeñar diversos cargos diplomáticos, regresó al país y se hizo cargo de la dirección del El Colegio de México, y siempre fue un mentor de Cuadernos Americanos. Para conocer más de la obra de Reyes como promotor cultural, ver Garciadiego, 2015, entre otros textos del mismo autor.
} 
Cosío Villegas, Alfonso Reyes, Rodolfo Usigli, Leopoldo Zea, Edmundo O'Gorman, Samuel Ramos, Silvio Zabala, Octavio Paz, y muchos más: lo más granado del pensamiento histórico, literario y arqueológico de México se dio cita en las páginas de la revista.

Si algo caracterizó los primeros años de Cuadernos Americanos fue, por parte de todos los que escribieron en ella, "la búsqueda apasionada y plural del conocimiento y el debate sobre América Latina" (González Neira, 2009, p. 21). La división en cuatro apartados ${ }^{9}$ permitió que una variedad de ideas se expusiera en sus páginas: desde comentarios sobre la situación actual en Europa y la Guerra, hasta arqueología mexicana; crítica literaria y ensayos diversos, e incluso, textos sobre ciencia, producto tanto de hombres como mujeres, algunas de ellas, destacadas científicas que por el conflicto bélico se habían exiliado en México ${ }^{10}$.

Por la necesidad de encontrar patrocinadores que apoyaran el financiamiento de la revista, encontramos anuncios publicitarios de una gama muy amplia: editoriales, refresqueras, tabacaleras, cerveceras, Petróleos Mexicanos. No existía en esa época ningún prejuicio en contra de la promoción y distribución de productos potencialmente dañinos para la salud.

\section{$\mathrm{V}$}

¿Por qué pueden ser de interés los Imaginarios socioculturales que expresaron y defendieron estos dos grupos de intelectuales, uno el de los mexicanos y otro el de los transterrados españoles? Si bien a cada grupo

\footnotetext{
9 "Nuestro Tiempo", basada en ensayos sobre asuntos de actualidad, referidos a la guerra, la situación de Europa y los actores principales en el ámbito internacional; "Aventura del Pensamiento", sobre cuestiones científicas, descubrimientos en torno al átomo por ejemplo, y cuestiones propiamente filosóficas; "Presencia del Pasado", que introdujo al debate los descubrimientos sustantivos en esa materia que estaban produciéndose en México y América Latina; y finalmente "Dimensión Imaginaria", con poemas y discusiones sobre arte y literatura.

${ }^{10}$ Es el caso de Marietta Blau, una colaboradora de Einstein, que, aunque no encontró las condiciones que requería en cuanto a laboratorios e interlocutores en México, estuvo en el país varios años (Blau, 1942).
} 
lo unía en cierto grado su semejante adscripción de nacimiento, mexicanos unos, españoles otros, lejos estaban de ser grupos homogéneos. Lo que quiero proponer en este trabajo es que los Imaginarios de las elites intelectuales, en un determinado momento y lugar, son una muestra clara de los diversos ideales, perspectivas y conflictos de una época, y pueden dar una idea del horizonte cultural en el cual se encuentra una sociedad, la mexicana, en este caso.

Los Imaginarios sociales son constructos simbólicos, los cuales se expresan y objetivan en representaciones sociales que muestran visiones del mundo, proyectos políticos, ideales y prejuicios prevalecientes en una sociedad, y permiten advertir los derroteros que esa sociedad toma en el presente y hacia dónde va en el futuro. Los Imaginarios sociales ayudan a comprender cuál es la visión que las personas - en el caso que nos ocupa, sectores de las elites intelectuales en México, en un momento crucial de su historia - tienen del mundo y de su propio papel en él. Pueden referirse a cuestiones si se quiere "macro" (los proyectos societales y los proyectos de nación; las formas de organización social, la economía, los ordenamientos políticos) o a cuestiones más ligadas con la vida cotidiana (la definición de quiénes conforman las clases subalternas, qué papel se les asigna, cómo se los caracteriza; cómo se caracteriza a las mujeres; el rol de la vestimenta, los gustos, los estilos de vida). En cada sociedad y momento, existe una gran cantidad de imaginarios, muchas veces confluyentes y complementarios, y otras, claramente contrapuestos en distintos grupos de la población.

Permítaseme hacer una introducción al tema: las ideas en torno a los imaginarios son variadas, complejas y abren un campo inmenso a la investigación y a la reflexión. El interés por los Imaginarios y las representaciones sociales ha sido parte de un proceso que comenzó en la segunda mitad del siglo XX en varios países, pero que en América Latina se dio con 
gran fuerza, sobre todo con posterioridad a lo que en sociología llamamos en su momento "la crisis de paradigmas" de la década de los años ochenta. Esta crisis, que fue sobre todo un movimiento de debate y rechazo a los modelos de análisis sociológico de carácter pan explicativo como el estructural funcionalismo y el marxismo que habían predominado en momentos anteriores, con diferente énfasis y fortuna en muchos de nuestros países, abrió la posibilidad de nuevos enfoques y perspectivas. Fue, por lo tanto, una crisis de crecimiento que marcó un momento de oportunidad y mostró nuevos intereses en el estudio de lo social: la acción, el sujeto, lo simbólico. O sea, el sentido de la acción y las relaciones humanas, sus significados, sus componentes tanto materiales como aparentemente intangibles, los procesos de interacción constructores de mundo y por lo tanto el carácter construido del mundo social. Como parte de ese movimiento reflexivo e innovador, surgen y se consolidan los estudios del imaginario social como elemento fundante de la inteligibilidad del mundo social y promotor de la acción.

En México, la investigación en torno a Imaginarios y Representaciones sociales se desarrolló con fuerza en la década de los años 90, continúa dando frutos hasta ahora y esperamos que durante mucho tiempo más.

Mi propia definición de lo que son los Imaginarios sociales es deudora de influencias diversas: tanto de Durkheim, como de Weber, Schutz, obviamente Cornelius Castoriadis, Charles Taylor, Juan Luis Pintos, Manuel Antonio Baeza, y muchos otros, a los que no hago responsables de lo que voy a plantear aquí. Desde mi perspectiva, conviene hablar de los imaginarios sociales siempre en plural, porque, en cada sociedad y época, coexisten varios Imaginarios, tanto en el plano más abstracto y general (los que Castoriadis Ilamaba centrales), como otros referidos a ámbitos específicos como lo urbano, la migración, o la educación. Imaginarios sociales son, entonces, las ideas e ideales, los valores, las imágenes del mundo y de la propia sociedad y época en la que a seres humanos les toca vivir, las utopías e ilusiones, las convenciones y expectativas sociales 
más generales y compartidas, que sirven a sus usuarios como esquemas o marcos de trasfondo para ubicar y comprender las situaciones en las que viven. La realidad social es producto de una construcción (mental, colectiva y también material) que los actores sociales realizan a través de sus relaciones, en las cuales intercambian ideas, creencias, informaciones, proyectan y ejecutan acciones, y construyen imágenes y artefactos. Los Imaginarios son construcciones simbólicas que posibilitan la inteligibilidad de la experiencia, como diría Manuel Antonio Baeza (2000; 2003; 2008), y permiten crear, instituir y modificar a las sociedades concretas, a la vez que cada sociedad o grupo constituye como Imaginarios un cúmulo de significaciones específicas que hacen referencia, entre otras cosas, a lenguajes y esquemas de interpretación, reglas de producción y reproducción de las instituciones, reglas de lo permitido y lo prohibido, de lo lícito o ilícito, aspiraciones y expectativas, cosmovisiones y utopías. Son espacios de producción y reproducción de memoria, prejuicios y creencias y fundamentan la economía moral ${ }^{11}$ y afectiva ${ }^{12}$ de una sociedad.

Baeza señalaba que, en cada sociedad, existen Imaginarios dominantes y dominados. Por lo tanto, para su estudio, hay que considerar sus relaciones con el poder, porque los Imaginarios son espacios de confrontación y lucha por la apropiación de la legitimación simbólica (Baczko, 1999). Son tanto estabilizadores como motivadores del cambio. Conectan el pasado (como historia y como memoria), el presente (como propiciadores de acción institucionalizada y/o institucionalizante), y el futuro (proponiendo otras formas de sociedad posible, incluso utopías).

Según Charles Taylor, los imaginarios sociales se refieren a los modos en que las personas imaginan su existencia social, al tipo de relaciones que

\footnotetext{
${ }^{11}$ Para E. P Thompson la economía moral es el conjunto de normas, valores y reglas que siguen las personas en una sociedad y época determinadas y que permiten definir lo que es aceptado y legítimo, y lo que no (Thompson, 1984).

12 Norbert Elías define a la economía afectiva como el conjunto de los comportamientos convencionalmente aceptados en una sociedad, destinados a la satisfacción de necesidades fisiológicas, emocionales y de decoro (Elías, 2016).
} 
mantienen unos con otros, al tipo de cosas que ocurren entre ellas, a las expectativas que se cumplen habitualmente y a las imágenes e ideas normativas más profundas que subyacen a estas expectativas. Para Taylor, el imaginario social es la concepción colectiva que hace posible las prácticas comunes y un sentimiento ampliamente compartido de legitimidad (Taylor, 2006).

De todo esto, lo que voy a retomar aquí es el carácter epocal de los Imaginarios, sus diferentes niveles o dimensiones de generalidad, su capacidad de impregnar la vida de las personas brindándoles la posibilidad de entender el mundo en el que viven, y orientar su actividad y las relaciones con los demás; la profunda imbricación de los Imaginarios con el poder en tanto son percibidos, de manera más o menos consciente, como vehículos para la obtención de legitimidad; y, sobre todo, el hecho de que son ámbitos de contraposición, de lucha, de conflicto, entre visiones del mundo, de la sociedad y del momento histórico.

También hay que tener en cuenta que las diversas clases y grupos de una sociedad pueden, en un momento determinado, fundamentar su actividad en ideas y expectativas diferentes; pueden, las personas y los grupos, encontrar su razón de ser y sustentar sus emociones y anhelos en distintos Imaginarios que operan como supuestos de trasfondo, no conscientes e implícitos, pero que pueden percibirse a través de los discursos y representaciones a los que acuden para expresarlos.

En este trabajo, voy a tratar de mostrar la presencia de imaginarios confluyentes y contrapuestos, perceptibles en las acciones, discursos, iconografía, propaganda y reproducciones de obras de arte, generados por algunos grupos que considero formaban parte de las élites intelectuales en la era del "milagro mexicano". Quiero aclarar que mi propuesta no tiene pretensiones de exhaustividad. Ni son todos los Imaginarios que muestro los que estaban presentes, ni los que muestro abarcan el riquísimo entramado simbólico del momento. Voy simplemente a ejemplificar, a mostrar 
una serie de ideas acerca de la existencia, en una sociedad determinada, en un periodo determinado, de Imaginarios diversos en torno a una misma cuestión: la idea de México. Con su red de conceptos asociados: lo mexicano, el mexicano. $\mathrm{Y}$ de los habitantes originarios del territorio que llamamos México. Si bien para mostrar lo que quiero discutir aquí voy a tomar un caso particular, creo que lo que puede extraerse son conclusiones más o menos generales que abonarían el debate en cualquier otra sociedad y momento histórico. Mi hipótesis es que, además de la presencia, en cualquier sociedad y época, de Imaginarios más o menos hegemónicos a la par de Imaginarios más o menos subordinados, existen Imaginarios contrapuestos, que conviven y se constituyen en ámbitos de confrontación e incluso de conflicto, sin lograr un claro predominio de unos sobre otros, pero que, en conjunto, constituyen el horizonte simbólico, cultural y aspiracional de esa sociedad en esa época determinada.

Claro, esto es tema de investigación empírica, pero a riesgo de pecar de audaz, creo que las inferencias teóricas se pueden sostener. Para hacerlo, me apoyaré en las representaciones e ideas que sobre México aparecen en la revista Cuadernos Americanos, revista que acabo de mencionar en el apartado anterior.

En los ensayos de destacados intelectuales mexicanos y extranjeros publicados en sus distintas secciones, en la iconografía (ilustraciones, fotografías) presente en sus páginas, y en las imágenes y slogans de su publicidad, podemos encontrar claras expresiones de los Imaginarios subyacentes, lo que permite, espero, mostrar el carácter plural y contrapuesto de los Imaginarios. 


\section{Los Imaginarios del indio, de las culturas prehispánicas y el indigenismo}

Una reconocida antropóloga mexicana, Alicia Barabas (2000), encuentra que fue desde la colonia que se constituyó un imaginario racista sobre los indios, que fueron caracterizados como salvajes y bárbaros. La barbarie podía ser consecuencia de su diferencia y su lengua, y el salvajismo, porque eran seres silvestres que vivían en espacios no urbanizados, andaban desnudos y comían comida cruda o recolectada en los campos. Los estereotipos denigratorios del indígena se basaban en los estigmas que, según los colonizadores, les eran propios: idolatría, sacrificio humano, canibalismo, brujería, poligamia, incesto y sodomía. Durante cinco siglos, se consideró que el bárbaro salvaje podía dejar de serlo, parcialmente, por la conversión religiosa; a partir del siglo XIX, podía lograrlo por vía de la razón y la educación. Los imaginarios acerca del indio mexicano se modificaron después de la Revolución Mexicana, y se pasó a considerarlos como objetos de integración forzosa, a través de la castellanización. Si bien se manejó el arquetipo del indio ancestral como parte de la identidad nacional, los millones de indígenas vivos eran un obstáculo para la unidad y homogeneización de la nación, y una pesada carga económica, cultural y política.

¿Cuál es la situación con respecto al Imaginario del indio que prevalecía en la época a la que quiero referirme? Por una parte, en la revista Cuadernos Americanos pueden encontrarse artículos que se refieren a los vicios de los indios, o a sus incapacidades o carencias (López Portillo, 1944), pero también, en otros artículos, a su ingenuidad, bonhomía y amabilidad. Lewis Hanke ${ }^{13}$ (1949) señala que desde la conquista

\footnotetext{
${ }^{13}$ Hanke fue un destacado historiador, hispanista e hispanoamericanista estadounidense conocido en México sobre todo por sus estudios sobre fray Bartolomé de las Casas, y puede ser considerado como el padre de los estudios latinoamericanistas en los Estados Unidos.
} 
existieron dos ideas fundantes con respecto a los indios: la de Fray Bartolomé de las Casas (los indios son gente sencilla y sin malicia), que luchó contra la idea aristotélica de que algunos hombres son por naturaleza esclavos y que esto podía aplicarse a los indios; y la de Gonzalo Hernández de Oviedo y Valdés (los indios son perezosos, viciosos, melancólicos, cobardes, indolentes e ingobernables). Incluso otro autor extranjero, Norbert Fryd ${ }^{14}$, maravilloso fotógrafo, relata su encuentro con los lacandones, a quienes se refiere como a "salvajes imberbes, con rasgos marcadamente femeninos por su suavidad, descalzos, con el cabello largo y de color negro azulado, rostro pálido, amarillo, que vestían una túnica larga, burdamente tejida y sucia pero que eran pacíficos, amables, encantadores y polígamos" y llega a preguntarse si estos nativos del sureste mexicano, que para la época tenían poco contacto con la civilización, no daban muestras de ser mucho más civilizados que los occidentales que pretendían robarles sus tierras y su madera (Fryd, 1948).

Y aquí es posible detectar, entonces, imaginarios contrapuestos coexistentes: por una parte la antigua idea del conquistador/colonizador acerca de que los vicios del carácter y las costumbres de los pueblos nativos los hacen inferiores, inaceptables para la vida moderna y, por lo tanto, el mejor indio es el indio muerto, o al menos subordinado; por otra, el Imaginario del indio como "el buen salvaje" de Rousseau, en el que se exaltan su pasividad, su falta de ambición, su carácter de "seres de naturaleza" a los que hay que proteger $y$, entre otras cosas, fotografiar para tener un registro de sus indumentarias y aspecto; $y$, finalmente, el

\footnotetext{
${ }^{14}$ Agregado cultural de la embajada de Checoslovaquia en México, realizó en marzo de 1948 un viaje a Bonampak donde tomó fotografías de los hachwinick o "gente verdadera", llamados lacandones por los españoles y conformó un archivo que donó posteriormente al Museo Nacional y que ahora se encuentra en el Acervo Fotográfico de la Biblioteca Nacional de Antropología e Historia de México. Es llamativo que en ese mismo año varias fotografías aparecieran en el número cuatro de Cuadernos Americanos, lo que es una muestra de las amplias conexiones sociales y políticas de los gestores de la revista.
} 
Imaginario que encontramos expresado en la políticas del Instituto Nacional Indigenista, fundado en el año de 1948, que implicó la necesidad de la integración, a través de la castellanización de los 10 millones de indígenas, borrando sus costumbres y tradiciones ${ }^{15}$, aunque exaltando las culturas indígenas ancestrales y sus monumentos como Chichen Itzá, Teotihuacán, Monte Albán o Palenque.

El tema indígena comenzó a tratarse en México desde la década de los años treinta, con Manuel Gamio al frente de diversas instituciones que llevaron ya en los cuarenta a la fundación del Instituto Nacional Indigenista. Pero, al decir de Guillermo Bonfil, la política nacionalista e indigenista del Estado mexicano era una propuesta etnocéntrica de integración y asimilación de los indígenas, a quienes se les negaba el derecho de mantener sus culturas propias (Bonfil, 1970). Cuadernos Americanos fue uno de los principales ámbitos para el debate entre los Imaginarios divergentes y contrarios, a través de los textos de destacados exponentes. En estrecha relación con estos Imaginarios contrapuestos, aparece en las páginas de Cuadernos Americanos el debate sobre la identidad mexicana.

\section{Los imaginarios acerca de la identidad del mexicano}

Encontramos en la revista Cuadernos Americanos varios materiales que sostienen lo que yo llamo "el imaginario de la carencia" y que se basan en ideas que tienen que ver con lo que supuestamente le falta al mexicano, a sus características provenientes del mundo indígena, a los mitos en torno al mestizaje, a sus esfuerzos de blanqueamiento, y a la imposibilidad de lograr una modernidad propia, que resulta, por lo tanto,

\footnotetext{
${ }^{15}$ Esta concepción del indigenismo perduró hasta la década de los años setenta, cuando se comienzan a aceptar las ideas del multiculturalismo, y a ver a la sociedad mexicana como pluriétnica y multicultural, a rescatar las costumbres y tradiciones, y valorar las lenguas indígenas, ya en peligro de extinción por la política anterior.
} 
en una imitación bizarra de la cultura de las sociedades del norte (Estados Unidos y sobre todo Europa). Este imaginario, el de la carencia y las frustraciones del mestizaje, va a perdurar durante mucho tiempo en la sociedad mexicana y en varias de Latinoamérica, pero lo que quiero mostrar aquí son algunos ejemplos de ese imaginario en la revista.

Los textos con los que quiero ejemplificar son de Octavio Paz, el nobel de literatura mexicano que, antes de publicar en 1950 su obra El laberinto de la soledad, pre-anunció lo que en ella iba a tratar en varios artículos en Cuadernos Americanos. Paz se hace eco del pensamiento de otro autor, Samuel Ramos, que sostenía que el mexicano tenía un sentimiento de inferioridad y una instintiva desconfianza en sus propias capacidades. Paz dice que el mexicano es un ser que se encierra y se preserva, tiene una máscara en el rostro y su sonrisa es una máscara de su identidad; y toma su experiencia en la ciudad norteamericana de Los Ángeles donde en esa época se podía encontrar al "pachuco", un mexicano migrado, furtivo, inquieto, que temía la mirada ajena y por eso se disfrazaba, exaltando una estética de descuido y fausto, el gusto por los adornos, la negligencia, la pasión y a la vez, la reserva (Paz, 1949; 1950).

Fernando Benítez, un autor que fue posteriormente importantísimo en el análisis de los problemas de los indios en México, señala, por su parte, las características de la sociedad mestiza, haciéndose eco de todos los prejuicios denigratorios de la época (Benítez, 1947). Emilio Uranga, discípulo mexicano de destacados filósofos españoles transterrados, como José Gaos, y del mexicano Leopoldo Zea, busca en un artículo titulado "Ensayo de una ontología del mexicano" sustituir la idea de la inferioridad del mexicano de Ramos, por la de insuficiencia. El mexicano, dice, es caracterológicamente sentimental, con una fuerte emotividad, inactividad, melancolía, disposición a rumiar interiormente todos los acontecimientos de la vida, tiene una fragilidad interior, un desprecio por la 
vida humana y vive en una constante acechanza de la muerte (Uranga, 1949; 2013)

¿Esto se puede remitir al chiste mexicano de un tipo que le pregunta a otro "cómo te llamas?" y el otro le contesta "Juan", a lo que el primero, disparándole con su revólver le dice "pum pum, te llamabas"). El mexicano es desganado (por eso se insta a los niños y jóvenes con un dicho "échale ganas" para que hagan su tarea o lo que tengan que hacer) y Uranga dice que esa desgana, el dejar todo para mañana, es una desgana por no ser otro. El mexicano, según Uranga, es huraño, retraído, pronto a defenderse (aquí, otro dicho: "se me hizo fácil", para justificarse). Los imaginarios presentes en todas estas interpretaciones del "carácter del mexicano" (si es que existe algo así...) muestran un prejuicio con respecto a la propia identidad, denigratorio, homogeneizante y reduccionista, que refleja la añoranza de los autores por una identidad "otra", la del europeo (el padre violador y potente y por lo tanto admirado del libro señero de Paz), y que consideran a la mexicana (violada, "chingada") una cultura de la imitación, fallida, falsa. Dice Paz que, en México, conviven varios niveles históricos (él así los llama) superpuestos y diferentes entre sí (hoy los llamaríamos grupos con intereses, cultura e imaginarios divergentes y coexistentes): hay quienes viven antes de la Historia, otros, como los otomíes (un grupo indígena del centro del país) al margen de ella, grupos católicos junto con otros jacobinos, el neo-feudalismo porfirista sirviéndose del positivismo, una educación socialista en un país de incipiente capitalismo, etc. Sólo una minoría de mexicanos tiene consciencia de sí. Para Paz, la historia de México es la historia del hombre que busca su filiación, su origen. Uranga dice que el indigenismo es el último proyecto de justificación inferior. Como al extranjero le fascina lo indígena, el mestizo mexicano mistifica y reivindica lo indio (no al indio).

Coexisten, en las páginas de la revista, entonces, estudios muy serios sobre las culturas y las etnias de México, como los de José Othón de Men- 
dizábal, que propone un mapa de los grupos indígenas que habitaban el territorio de la república (Mendizábal, 1942; 1943; 1945) junto con estudios de arqueología mexicana (Caso, 1942; 1942b; 1942c) (donde obviamente se exalta el pasado, la sección donde se publican se llama "Presencia del pasado"), junto con estudios que cuestionan el mito del mestizaje (la idea de México como una sociedad mestiza: racialmente híbrida, progresivamente blanca, y culturalmente española) y la visión indigenista que desde las esferas del gobierno se impulsaba. El imaginario del México mestizo implicaba tanto el supuesto valorativo subyacente acerca de la inferioridad del indígena, como la necesidad del "blanqueamiento progresivo" ya fuera por la integración forzosa, como por la educación o el ascenso social, del cual la educación era un posible motor.

El imaginario del blanqueamiento progresivo fue y sigue siendo una aspiración sumamente potente que encontramos en una frase comúnmente escuchada, aún hoy: "hay que mejorar la raza". Y una muestra del blanqueamiento aspiracional fue la iconografía que aparece en las páginas de la revista, tanto en los anuncios de productos considerados como símbolo de la modernidad (una modernidad que en esa década comenzaba a intentar imitar el american way of life, como veremos más adelante) como en aquellos cuyo consumo garantizaba un alto estatus.

Los anuncios de Coca Cola, con personajes blancos, rubios, y los de cigarrillos Belmont, con elegantes hombres y mujeres saliendo del teatro o de la ópera, o jugando al golf, cosas totalmente extrañas para el común de la gente, pero que podían simbolizar el tipo de vida al que podían aspirar, claro, si consumían dichos productos. Obviamente, ni el director, el mexicano Jesús Silva Herzog, ni el secretario de la revista, el español Juan Larrea, ambos destacados intelectuales, hicieron un análisis de lo que las imágenes de la publicidad significaban (entre otras cosas, porque necesitaban desesperadamente de las subvenciones que las empresas les proporcionaban). 
Imaginarios contrapuestos: los que nutren la consciencia de la crisis, y los de la utopía

El tema y los análisis acerca de la crisis son recurrentes en la revista. ¿De qué crisis se trata? En primer término, de la crisis de la cultura europea, tanto la que ocasionó la Segunda Guerra Mundial como, después del triunfo de los aliados, la crisis general de la posguerra, sobre todo en los planos económicos y de la cultura. En plena guerra, el secretario de la revista, Juan Larrea, en su famoso debate con José Iturriaga, dice que "la unión de la URSS y los países capitalistas contra el nazismo y el fascismo han oscurecido los objetivos de la revolución" [socialista, debemos suponer, que formaba parte del ideario político de muchos de los expatriados españoles] (Larrea, 1942), y ve la situación de Europa como catastrófica. Para Recaséns Siches, otro transterrado a México, lo ocurrido desde 1933 en Alemania ha significado sólo re-barbarización y envilecimiento (Recaséns Siches, 1942). El mexicano Iturriaga considera, por el contrario, que la Guerra implica una expulsión del morbo [la enfermedad] acumulado en Europa, no la decadencia de la cultura europea. Lo que allí surja, dice, será una sociedad con una organización racionalizada, purificada, sana, ascendente (Iturriaga, 1942).

Pero también se discutió abundantemente sobre la crisis de México, o más bien, la crisis de la idea y del proyecto de México fue un tema ampliamente debatido en las páginas de Cuadernos Americanos. Ya en el primer número, Alfonso Reyes señalaba la profunda inquietud que sentían por lograr que América llegara a ser lo que debe ser, y cuáles eran las condiciones para que ello sucediera (Reyes,1942). Se habla de América, pero en realidad se piensa en Latinoamérica y específicamente en México, no sólo durante la Guerra, sino en lo que va a pasar posteriormente, en el papel que la nueva situación mundial le ofrecería a México y a América Latina (Silva Herzog, 1945; Villaseñor, 1944). 
Los ideales de la Revolución Mexicana, según varios de los autores que vamos a comentar, para esas fechas han perimido, se han abandonado e incluso traicionado. ¿Quiénes son los que hablan de la crisis? Los que Enrique Krauze, un autor muy conocido en México, ha denominado "los hijos desencantados de la Revolución". Los que, por ser demasiado jóvenes, no participaron en el proceso armado revolucionario propiamente dicho, pero que ya en la Universidad adoptaron sus objetivos y se dedicaron a estudiar y a formarse, tanto en México como en el extranjero, y que a fines de los treintas y en la década de los cuarenta, frustrados y desencantados por el camino que tomaban las instituciones del país, instituciones en las que ellos participaban activamente, se apartaron; unos, fundando partidos de oposición y otros, encabezando empresas culturales para promover el conocimiento y la cultura en México. El caso de Daniel Cosío Villegas, comentado más arriba, es una muestra ejemplar de esta situación: como no pudo ver satisfechas sus aspiraciones políticas, encaminó sus esfuerzos a la creación de instituciones: El Colegio de México, y el Fondo de Cultura Económica, transformando el exilio español en México y su propia exclusión del gobierno en una empresa cultural exitosa.

Cosío escribió, en 1947, en Cuadernos Americanos, un artículo que fue muy comentado, donde criticaba acerbamente el derrotero que había tomado la Revolución, cuyo programa, y por lo tanto la idea de México que en él se había configurado, se había agotado, entre otras cosas, porque los hombres de la Revolución Mexicana habían resultado inferiores a las exigencias de ella. Los hombres de la Revolución eran ignorantes, gobernaban por instinto, y fueron muy buenos para destruir la estructura social jerárquica y el latifundio, pero no crearon formas nuevas. Si bien se hizo mucha obra, carreteras, escuelas, etcétera, los progresos sociales y cívicos eran mezquinos y mediocres. Cosío denuncia la corrupción imperante, la crisis política y moral, y también denuncia algunos de los mitos 
de origen que, impulsados por la colonización y luego por personajes como Humboldt, sostenían que México era un país rico, algo así como el "cuerno de la abundancia"; mitos que ocultaban las tremendas carencias materiales de la mayoría de la población del país. Llamaba, por lo tanto, a conocer científicamente la realidad de México para cambiarla y veía un futuro incierto. Estas ideas eran compartidas por autores que también escribieron sobre la crisis de México, sosteniendo que, en la década de los años cuarenta, la Revolución ya era un hecho histórico. Por ejemplo, entre otros, el director de Cuadernos Americanos, Jesús Silva Herzog, que se refería a la crisis de México más o menos en los mismos términos que Cosío (Silva Herzog, 1943; 1949) ${ }^{16}$, y también Iturriaga (1947). O que México, la tierra de la esperanza y la utopía, se había convertido en una nave que iba a la deriva, porque no se supo imponer a hombres rectos y de talento en los puestos de mando, y denunciaban las condiciones de ignorancia y miseria en las que aún vivían 8 millones de indios y 15 millones de campesinos, obreros y empleados frente a los 5000 privilegiados a los que México no les importaba (Benítez, 1948).

Frente a esta consciencia de la crisis, nutrida del Imaginario de la Revolución, el cual suponía cambios sociales profundos que los principales intelectuales de México plasmaron en las páginas de la revista, estaba el Imaginario utópico de los migrantes que veían a México como tierra de promisión, donde la cultura humanista y las oportunidades personales podrían crecer y desarrollarse. Un imaginario compartido por algunos de los intelectuales mexicanos que escriben en la revista, en el fragor de la segunda guerra mundial, como Alfonso Reyes, por ejemplo, para quien "América aparece [...] como el terreno más propicio para heredar y fun-

\footnotetext{
16 No es casual que esta visión crítica de la realidad mexicana proviniera de estos autores, ambos con formación en economía, o, en el caso de Benítez, científico social especializado en demografía, ya que se basaban en hechos comprobados, y no en ideologías o meras suposiciones o expresiones de deseos.
} 
dir las culturas anteriores, en un sentido de universalidad hasta hoy no alcanzado" y "...el mundo estaba nublado, sin nublar por ello nuestra esperanza" (Reyes, 1942).

Vale la pena detenernos un momento para resaltar el papel de Cuadernos Americanos en los debates sobre la identidad, la cultura, el presente y el futuro, y el papel de la historia, debates que incidieron profundamente en el horizonte cultural de México. ¿Cuál era "la idea de México" que traían muchos de los llamados transterrados españoles? Por un lado, que el lugar a donde llegaban después de un viaje azaroso y múltiples infortunios era "una tierra de promisión", donde la Humanidad podía buscar refugio, y donde habría de surgir una nueva era de saber y paz. En América surgiría, tras el desastre y la decadencia de Europa, una sociedad nueva (Tierno Tejera, 2010).

El poeta bilbaíno Juan Larrea fue el secretario y real fac totum de la revista, a la que contribuyó de mil maneras, entre otras, con el diseño de la portada. Y ya en la portada, podemos ver una representación del Imaginario que tanto Larrea como Eugenio Ímaz, León Felipe y otros republicanos españoles exiliados tenían sobre el país al que llegaban: cada número mostraba, en diferentes colores, ondas que representaban el mar, el trayecto/tránsito a través del cual se podía llegar a la tierra donde la cultura humanista de la vieja Europa podía afincarse y florecer de nuevo con renovados bríos. En los textos de Larrea, encontramos recurrentes metáforas referidas a la tierra de refugio: las orillas, las playas, la aurora, el alba de oro. También, unas reflexiones que serán frecuentes en la revista, sobre la crisis de la cultura humanista europea (Larrea, 1942).

Ya en el primer número de la revista, en las primeras páginas, aparece una ilustración, el mapa de América con dos leyendas: "América, tú eres mi esperanza, tú estás llamada a salvar al mundo" del presidente español Francisco Pi y Margall, y otra frase de Rubén Darío que dice 
"América es el porvenir del mundo". En ese primer número, el mismo Juan Larrea dice que "la evolución en el tiempo de Europa, de la civilización occidental, la ha conducido al extremo límite de sus posibilidades, allí donde se vislumbra la otra ribera y cuaja el fruto que contiene la semilla de la civilización futura... mas, para arribar a las playas del mundo nuevo...es preciso embarcarse, es preciso morir en una orilla para nacer en la otra". En otro de sus textos, que dio pie a una serie de debates con otros intelectuales en las páginas de la revista y en otras, señala que la barbarie de Europa, el monstruo al que han permitido crecer, es señal de un profundo cataclismo. Frente a esta fase de violencia y ruptura, esencialmente inhumana, en que forcejean el individualismo feroz y las masas enfurecidas, tenemos el fraguado de un mundo nuevo, libre y pacífico, ya que el camino de la universalidad pasa por América. Estas ideas, tan extremas, sobre la debacle europea y el mítico destino de América, y por lo tanto de México, el país que lo acogía, fueron refrendadas por Larrea en un carta posterior a las contiendas, dirigida al director Reyes Heroles, en 1950, cuando, próximo a ir a Estados Unidos, becado por la Fundación Guggenheim, abandonaba su puesto en Cuadernos Americanos: "tengo la creencia de que el continente americano está llamado a realizar aportes de conciencia necesarios para infundir caracteres de mundo nuevo y distinto a ese todo cultural naciente por ser propio de su destino dar cuerpo, al contacto con la universalidad, a una entidad diferenciada, a un hombre y a una cultura nuevos". El lenguaje místico, la sublimación de la idea de América y México, son propios del Imaginario utópico que nutría el pensamiento de Larrea y otros exiliados.

Otros autores, tanto mexicanos como españoles, tenían una idea menos mítica acerca de México y las posibilidades de América en general. José Iturriaga, un joven que poco tiempo después publicaría un trabajo importantísimo para el desarrollo de la comprensión de la realidad mexi- 
cana ${ }^{17}$, con una visión más realista con respecto a la situación europea, sostenía que lo que surgiera de la guerra sería una sociedad con una organización racionalizada, purificada, sana, ascendente, y específicamente le decía a Larrea: "No permita que la voluptuosidad de crear mitos lo extravíe y lo lleve a alinearse a bandos que ha combatido con denuedo. Un escritor modesto no tiene el derecho a estar mal informado, aunque sea poeta [...] vuelve usted a sacrificar la verdad en aras de un mito geográfico" (Iturriaga, 1942). Y otro exiliado, José Herrera Petere, titulaba un escrito en contra de Larrea y a favor de Iturriaga: "En contra de un absurdo y peligroso geografismo".

Estos Imaginarios contrapuestos venían a sumarse a los que se vieron más arriba, en torno a la crisis de México. Sobre todo por parte de Iturriaga y otros, venían a reafirmar la necesidad de observar la realidad mexicana y, principalmente, a profundizar en el estudio de su economía. Un Imaginario utópico y esperanzado frente a un Imaginario también esperanzado, pero fundado en la necesidad de conocer y actuar. No la llegada al Edén, sino formas y prácticas para, quizás, construirlo.

\section{Imaginarios de la modernización/ Imaginarios de la tradición}

Los Imaginarios que quiero mencionar ahora son también Imaginarios contrapuestos: el de la modernización, impulsado por el gobierno y las elites empresariales, que suponía cambios, sobre todo en el terreno de la economía - industrialización, inversiones extranjeras, desarrollo de las industrias extractivas, consumo -, en convivencia y contraposición con el de las tradiciones como elemento identitario fundamental.

Obviamente, el Imaginario de la modernización - qué era, qué se requería y qué implicaba entrar en la modernidad - se encuentra clara-

${ }_{17}$ Estudio social y cultural de México, 1951. 
mente plasmado en los discursos de los gobernantes de la época, y ha sido analizado por muchos autores, pero lo que quiero mostrar aquí son las representaciones de ese Imaginario en ejemplos muy claros en las páginas de Cuadernos Americanos. No sólo en artículos, donde se sostiene que México o se desarrolla o se hunde, y se proponen medidas concretas de política económica como el aumento de la tributación, el control salarial y de la paridad monetaria (Carrillo Flores, 1948), sino también en imágenes: un anuncio gubernamental que se repite en varios números muestra a una figura femenina, alta, delgada, blanca y rubia en actitud de avance, fuerte e impetuosa, enarbolando la bandera mexicana.

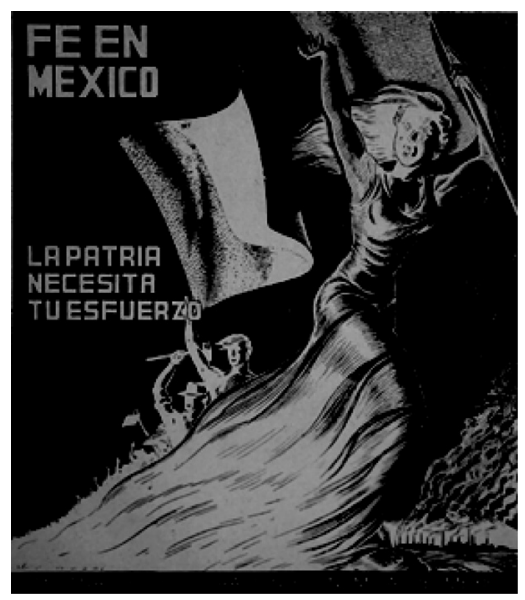

Extraída de Cuadernos Americanos, año VII, número 5.

La Patria que va hacia el futuro no representa étnico-racialmente a México, sino a la Patria utópica; los que la siguen, presumiblemente obreros, campesinos y empleados (por los instrumentos que portan) son también blancos y rubios. En la parte inferior derecha, fábricas humeantes, implican que la Patria moderna avanza hacia la industrialización. Los le- 
mas son "Fe en México", "la Patria necesita tu esfuerzo" y el anuncio lo firma la "Campaña de recuperación económica de México". La representación es de un México que no existe en la época, pero al que se aspira. En la imagen se mezclan entonces dos elementos constitutivos del Imaginario de la modernización: el que asocia desarrollo con el avance hacia adelante y el racista clasista del blanqueamiento de la raza que la modernización permite y favorece. La imagen parece extraída de los afiches de la Alemania nazi o del realismo socialista de la época, pero, más allá de eso, queda claro el mensaje para cualquiera que lo vea: adelante está el futuro que sólo se ganará con la industrialización y que traerá consecuencias identitarias evidentes. Los mexicanos se industrializarán y, con eso, dejarán de ser morenos, "prietos" (la palabra prieto, utilizada habitualmente en México indica no carnes apretadas, sino que refiere a una segunda acepción: algo que es oscuro casi negro). Lo que implica aspirar a ser lo que no se es, y despreciar lo que se es. Este es un conflicto identitario de vieja data en México, no es un invento del Estado posrevolucionario. Pero lo que impacta es que después de un proceso que implicó la entrada en el escenario político de sectores subalternos indios y mestizos, el imaginario racista aún perdure, y no sólo en la década que estoy revisando sino hasta la actualidad.

El Imaginario de la modernización, sustento de las políticas gubernamentales de la época, implicaba también cambios profundos en la vida cotidiana de las incipientes, pero en crecimiento, clases medias urbanas. Frente a una estructura patriarcal que recluía a las mujeres en su casa, dedicadas a las tareas del hogar, tediosas y pesadas, el Imaginario de la modernización nutría las representaciones de un futuro dorado: el del alivio de las tareas domésticas por la utilización de aparatos propios del confort moderno, y el estatus en ascenso a través del consumo de artículos con una pátina novedosa y prestigiosa proveniente de su origen extranjero - licuadoras, refrigeradores, lavadoras, aspiradoras. 
Ejemplos de esto: cuando en 1947 abrió la primera tienda Sears en la ciudad de México, los compradores se abalanzaron literalmente sobre los productos, al punto de que un autor que reseña el evento señalaba que agitando frenéticamente los pesos frente a la cara de los vendedores e intentando introducírselos en los bolsillos, querían garantizar sus compras. Aunque otras tiendas del mismo tipo existían en la ciudad, los artículos norteamericanos que la nueva ofrecía tenían el sabor de la modernidad ${ }^{18}$.

La Imagología ${ }^{19}$ o la iconografía ${ }^{20}$ y la publicidad presente en Cuadernos Americanos se hace eco de esta modernidad mexicana con aspecto estadounidense: los anuncios de nuevos productos, como la cerveza, que se intentaba sustituyera al tradicional pulque mexicano, exaltaban el carácter saludable de la nueva bebida; los anuncios de cigarrillos los asociaban con las clases acomodadas. Los anuncios de modernas cocinas y aparatos domésticos, por lo general mostraban a una mujer alta, delgada, de piel blanca, haciendo uso de dichos artefactos, símbolos del nuevo confort. La publicidad, a través de sus representaciones, mostraba el imaginario subyacente: el nuevo México moderno era confortable, avanzado y blanco.

Este Imaginario de la modernización se contrasta fuertemente con el Imaginario del valor de la tradición, sobre todo representado por la familia tradicional, la vida campirana, la inocencia de los personajes y la nostalgia de una vida bucólica.

\footnotetext{
${ }^{18}$ El puerto de Liverpool había abierto en 1847 y El Palacio de Hierro abrió sus puertas en 1891, con el propósito claro de dotar a México de tiendas de departamentos (secciones) a la altura de las mejores del mundo.

${ }^{19}$ Imagología estudia las imágenes mentales o imagotipos, se usa por la hermenéutica intercultural para estudiar estereotipos, mentalidades, prejuicios, actitudes, imágenes y otros conceptos afines. Los imagotipos son clichés sobre los pueblos y han sido materia de innumerables anécdotas itinerantes.

${ }^{20}$ Iconografía es el conjunto de imágenes relacionadas con un personaje o un tema y que responden a una concepción o a una tradición. También se refiere a un estudio u obra que describe y analiza las características de las imágenes relacionadas con un personaje o tema.
} 
En el caso de México en la revista Cuadernos Americanos, esa nostalgia por el pasado, por tradiciones ancestrales, se pone de manifiesto sobre todo en su iconografía compuesta de dibujos de monumentos coloniales o prehispánicos propios de cada importante ciudad del país, y lo más sugestivo es que, en los textos que acompañan a esos dibujos, aparecen con claridad los dos imaginarios contrapuestos: por una parte se recuerdan los hitos del pasado, y por otra, se ensalzan las virtudes modernizadoras del presente: la conexión por el ferrocarril con otras ciudades del país, el atractivo turístico de los lugares mencionados.

Cuadernos Americanos fue, entonces, un muestrario de los diversos conflictos presentes en la realidad, a través de sus expresiones y representaciones por parte de diferentes grupos de intelectuales, y en sus páginas se ha mostrado también que los Imaginarios no eran, ni son, homogéneos en un momento y lugar determinados, que no pueden reducirse a dualidades mutuamente excluyentes, sino que son espacios de confrontación, donde se juegan sentidos, aspiraciones e identidades.

\section{Reflexiones finales}

Ya para terminar, permítanme retomar algunas de las ideas que plantee al comienzo de este apartado, ya con la pretensión de generalizar ciertas conclusiones.

En todas las sociedades, existen, a la vez, Imaginarios construidos con niveles o dimensiones de generalidad diferentes: los más abarcadores, como los referidos a las ideas de Nación correspondientes, o los relativos a qué se entiende como sociedad moderna, o sobre características raciales/étnicas o culturales propias, o Imaginarios de género (que no abordé aquí). Otros Imaginarios tienen ámbitos quizá más acotados, por ejemplo, los Imaginarios urbanos, o rurales, o sobre los migrantes, o sobre 
la educación, que están estrechamente ligados a los primeros, pero que tienen una especificidad propia.

Todos los Imaginarios tienen una imbricación fuerte con el poder, en sus distintas manifestaciones, porque sirven como vehículos de obtención y mantenimiento de legitimidad, como fue el caso del Imaginario racista sobre los indios, o el Imaginario modernizador que acabamos de comentar.

Los diversos Imaginarios conviven, en estratos de significación diversos, en cada época y sociedad, y son ámbitos de confluencia de interpretaciones, pero también son espacios simbólicos de conflicto, contraposición y confrontación. Son espacios de lucha que abonan proyectos, programas y definiciones identitarias.

Los Imaginarios son epocales, o sea, cambian con el tiempo, y ayudan a definir los elementos sustantivos de cada momento histórico.

Las elites intelectuales expresan en sus obras esos imaginarios epocales que, con esas mismas obras, contribuyeron a construir. Quizás los grupos de intelectuales no sean los actores principales en una sociedad, no hay que olvidar a los gobiernos y los poderosos grupos de interés empresariales, de los medios de comunicación y demás, pero sí son constructores de cultura y, por lo tanto, críticos o legitimadores de los imaginarios sociales prevalecientes en un lugar y época determinados.

Lidia Girola es socióloga y Profesora-investigadora de Tiempo Completo en la Universidad Autónoma Metropolitana Azcapotzalco, México.

\lgirola2000@yahoo.com 


\section{Bibliografía}

1. BACZKO, Bronislaw. Los imaginarios sociales. Memorias y esperanzas colectivas. 2 ed. Buenos Aires: Ediciones Nueva Visión, 1999.

2. BAEZA, Manuel Antonio. Los caminos invisibles de la realidad social. Ensayo sobre sociología profunda sobre los imaginarios sociales. Santiago de Chile: Ril Editores, 2000.

3. BAEZA, Manuel Antonio. Imaginarios sociales. Apuntes para la discusión teórica y metodológica. Concepción: Editorial Universidad de Concepción, 2003.

4. BAEZA, Manuel Antonio. Mundo real, mundo imaginario social. Teoría y práctica de sociología profunda. Santiago de Chile: Ril Editores, 2008.

5. BAEZA, Manuel Antonio. Hacer mundo. Significaciones imaginario-sociales para constituir sociedad. Santiago de Chile: Ril Editores, 2015.

6. BARABAS, Alicia. La construcción del indio como bárbaro: de la etnografía al indigenismo. Alteridades, Universidad Autónoma Metropolitana - Unidad Iztapalapa, v. 10 n. 19, p. 9-20, 2000. [http://www. redalyc.org/articulo. oa?id =74701902]

7. BLAU, Marietta. El descubrimiento del electrón positivo. Cuadernos Americanos, año 1, n. 1, p. 73-82, 1942.

8. BENÍTEZ, Fernando. México: la tela de Penélope. Cuadernos Americanos, año 6, n. 1, p. 44-60, 1947.

9. BENÍTEZ, Fernando. En el principio era el mito. Cuadernos americanos, año 7, n. 6, p. 50-80, 1948.

10. BONFIL, Guillermo. Del indigenismo de la revolución a la antropología crítica en De eso que Ilaman antropología mexicana. México DF: Nuevo tiempo, 1970, p. 39-65.

11. CARRILLO FLORES, Antonio. El desarrollo económico de México. Cuadernos Americanos, año 7, n. 5, p. 42-59, 1948.

12. CASO, Alfonso. Los aztecas de México. Cuadernos Americanos, año 1, n. 1, p. 155-60, 1942.

13. CASO, Alfonso. ¿Por qué deben conservarse los restos de una antigua civilización? Cuadernos Americanos, año 1, n. 3, p. 122-32, 1942.

14. CASO, Alfonso. El paraíso terrenal en Teotihuacán. Cuadernos Americanos, año 1, n. 6, p. 127-36, 1942. 
15. COSÍO VILLEGAS, Daniel. La crisis de México. Cuadernos Americanos, año 6, n. 2, p. 29-51, 1947.

16. ELÍAS, Norbert. El proceso de la civilización. Investigaciones sociogenéticas y filogenéticas. Ciudad de México: Fondo de Cultura Económica, [1982] 2016.

17. FRYD, Norbert. Nota: Encuentro con los lacandones. Cuadernos Americanos, año 7, n. 4, p. 70-6, 1948.

18. GARCIADIEGO, Javier. Autores, editoriales, instituciones y libros. Estudios de historia intelectual. Ciudad de México: El Colegio de México, 2015.

19. GARCIADIEGO, Javier. Alfonso Reyes y La Casa de España en México. In: VALERO PIE, Aurelia. Los empeños de una casa: Actores y redes en los inicios de El Colegio de México 1940-1950. Ciudad de México: El Colegio de México, 2015, pp. 33-54.

20. GIROLA, Lidia. Imaginarios socioculturales de la modernidad. Aportaciones recientes y dimensiones del análisis para la construcción de una agenda de investigación. Sociológica, n. 64, p, 45-76, 2007. [http://www.redalyc.org/articulo. oa?id=305024715003]

21. GIROLA, Lidia. Representaciones e Imaginarios sociales. Tendencias recientes en la investigación. In: DE LA GARZA TOLEDO, Enrique; LEYVA, Gustavo (eds.). Tratado de metodología de las ciencias sociales. Perspectivas actuales. Iztapalapa: Fondo de Cultura Económica, 2012, pp. 402-31.

22. GIROLA, Lidia. Crisis como oportunidad. Grupos intelectuales y la construcción del Estado Post-revolucionario: Su contexto político e intelectual (19391950). Tempo Social, v. 38, n. 3, 2016.

23. GONZÁLEZ NEIRA, Ana. Cuadernos Americanos y el exilio español: nacimiento de una revista universal (1942-1949). Cuadernos Americanos, v. 1, n. 127, Nueva Época, p. 11-30, 2009.

24. HANKE, Lewis. La aportación de Fray Juan de Zumárraga a la cultura mexicana. Cuadernos Americanos, año 8, n. 4, p 163-71, 1949.

25. ITURRIAGA, José. México y su crisis histórica. Cuadernos Americanos, año 6, n. 3, p. 21-37, 1947.

26. ITURRIAGA, José y Juan Larrea. Hacia una definición de América. Cuadernos Americanos, año 1, n. 6, p. 7-33, 1942.

27. KRAUZE, Enrique. Daniel Cosío Villegas. Una biografía intelectual. Ciudad de México: Tusquets Editores, [2001] 2015.

28. KRAUZE, Enrique. Caudillos culturales en la Revolución Mexicana. Ciudad de México: Tusquets Editores, [1976] 2014. 
29. LARREA, Juan. Nuestra alba de oro. Cuadernos Americanos, año 1, n. 1, p. 51-74, 1942.

30. LOAEZA, Soledad. Modernización autoritaria a la sombra de la superpotencia, 1944-1968. In: VARIOS AUTORES. Nueva Historia general de México. Ciudad de México: El Colegio de México, 2010, pp. 653-98.

31. LÓPEZ PORTILLO, José. La incapacidad del indio. Cuadernos Americanos, año 3, n. 1, p. 150-62, 1944.

32. MENDIZÁBAL, Miguel Othón de. La evolución de las culturas indígenas en México y la división del trabajo. Cuadernos Americanos, año 1, n. 1, p. 120-31, 1942.

33. MENDIZÁBAL, Miguel Othón de. La conquista espiritual de la 'Tierra de Guerra' y su obstrucción por los conquistadores y pobladores. Cuadernos Americanos, año 2, n. 2, p. 123-36, 1943.

34. MENDIZÁBAL, Miguel Othón de. Los problemas indígenas y su más urgente tratamiento. Cuadernos Americanos, año 4, n. 4, p. 46-66, 1945.

35. NIBLO, Stephen. Mexico in the 1940s. Modernity, Politics, and Corruption. Willington: SR Books, 1999.

36. PAZ, Octavio. El laberinto de la soledad. Cuadernos Americanos, año 8, n. 5, p. 17-30, 1949.

37. PAZ, Octavio. El laberinto de la soledad II. Cuadernos Americanos, año 9, n. 1, p. 79-92, 1950.

38. RECASÉNS SICHES, Luis. El derrumbamiento de la cultura alemana. Cuadernos Americanos, año 1, n. 3, p. 7-28, 1942.

39. REYES, Alfonso. América y los 'Cuadernos Americanos'. Cuadernos Americanos, año 1, n. 2, p. 7-10, 1942.

40. SILVA HERZOG, Jesús. La revolución mexicana en crisis. Cuadernos Americanos, año 2, n. 5, 1943.

41. SILVA HERZOG, Jesús, ¿Y después de la guerra qué? Cuadernos Americanos, año 4, n. 6, p. 7-20, 1945.

42. SILVA HERZOG, Jesús. La revolución mexicana es ya un hecho histórico. Cuadernos Americanos, año 8, n. 5, p. 7-16, 1949.

43. TAYLOR, Charles. Imaginarios sociales modernos. Barcelona: Paidós Básica, 2006. 
44. THOMPSON, Edward P. La economía 'moral' de la multitud en la Inglaterra del siglo XVIII. En: THOMPSON, Edward P. Tradición, revuelta y consciencia de clase. Estudios sobre la crisis de la sociedad preindustrial. Barcelona: Editorial Crítica, 1984.

45. TIERNO TEJERA, Sofía. Colaboraciones de exiliados españoles en las revistas Cuadernos Americanos y El Hijo Pródigo: América como utopía. Ponencia. IX Congreso Argentino de Hispanistas, "El Hispanismo ante el Bicentenario". La Plata, Argentina, 2010. [http://ixcah.fahce.unlp.edu.ar]

46. URANGA, Emilio. Ensayo de una ontología del mexicano. Cuadernos Americanos, año 8, n. 2, p. 135-48, 1949.

47. URANGA, Emilio. Análisis del ser del mexicano. Y otros escritos sobre la filosofía de lo mexicano (1949-1952) Ciudad de México: Bonilla Artigas Editores, 2013.

48. VILLASEÑOR, Eduardo. América Latina en la economía mundial. Cuadernos Americanos, año 3, n. 4, p. 7-19, 1944.

49. WEINBERG, Liliana. Cuadernos Americanos: entre la memoria y la imaginación. Cuadernos Americanos, n. 50, Nueva Época, p. 13-22, 1995.

Recebido: 10.09.2017

Aceito: 31.10 .2017

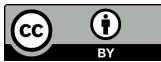

